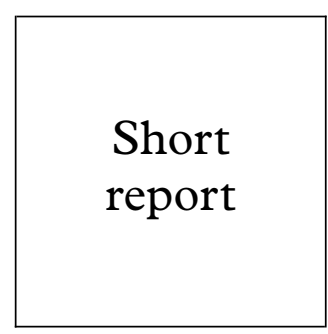

\title{
Antimicrobial susceptibility and plasmid profile of Neisseria gonorrhoeae in India (New Delhi)
}

\author{
P Bhalla, K Sethi, B S N Reddy, M D Mathur
}

Objectives: To determine the antibiotic susceptibility and plasmid profile of all Neisseria gonorrhoeae strains (PPNG and non-PPNG) isolated from May 1995 to March 1996 in Lok Nayak Hospital, New Delhi, India.

Methods: The agar plate dilution method was used to determine the minimum inhibitory concentration of five antimicrobials including norfloxacin and ceftriaxone which are most commonly used for treatment of gonorrhoea in Delhi. Isolates were screened for production of penicillinase by paper acidometric method and plasmid analysis of PPNG and non-PPNG was carried out by agarose gel electrophoresis.

Results: 50 consecutive isolates of $N$ gonorrhoeae were studied, $8 \%$ among them were found to be PPNG while $28 \%$ were highly resistant to tetracycline (TRNG). Reduced susceptibility to norfloxacin (MIC $\geqslant 1 \mu \mathrm{g} / \mathrm{ml}$ ) was observed in $12 \%$ of all isolates. All PPNG harboured the 4.4 $\mathrm{MDa} \beta$ lactamase plasmid along with the $25.2 \mathrm{MDa}$ tetracycline resistance plasmid. Norfloxacin resistance (MIC $\geqslant 1 \mu \mathrm{g} / \mathrm{ml}$ ) was present in $28.5 \%$ of TRNG but only in $5.5 \%$ of the other gonococcal isolates.

Conclusions: Results of this study clearly demonstrate that antibiotic resistant gonococcal strains of different clones are frequently found in New Delhi. Continued surveillance of susceptibility to currently prescribed antimicrobials and epidemiological studies are essential to prevent treatment failures leading to further spread of resistant strains.

(Sex Transm Inf 1998;74:210-212)

Keywords: antimicrobial susceptibility; Neisseria gonorrhoeae; plasmids; India

\section{Introduction}

The worldwide prevalence of gonorrhoea and the emergence of antibiotic resistant Neisseria gonorrhoeae reinforce the need for epidemiological study of this organism and surveillance of its susceptibility to antibiotics commonly used for therapy. Despite a high prevalence of gonorrhoea and an increasing incidence of penicillinase producing $N$ gonorrhoeae (PPNG) in India no standardised monitoring of antimicrobial susceptibility of $N$ gonorrhoeae has been adopted so far. ${ }^{1}$ During $1994-5$ we carried out a preliminary study on antimicrobial susceptibility of gonococcal isolates in Lok Nayak Hospital, New Delhi and found $5.3 \%$ of them to be PPNG (unpublished data). Plasmid analysis of eight PPNG isolates in Bombay, India revealed the presence of a 4.4 megadalton (MDa) $\beta$ lactamase plasmid in all the isolates, while three of them also carried the large $24.5 \mathrm{MDa}$ conjugative plasmid. ${ }^{2}$

Plasmid mediated high level resistance to tetracycline was first observed in 1985 in the United States. ${ }^{3}$ Since then tetracycline resistant $N$ gonorrhoeae (TRNG) strains have been reported from England $^{4}$ and central Africa. ${ }^{5}$ Although tetracycline resistance in $N$ gonorrhoeae has been reported from India, there have been no studies on plasmid mediated high level tetracycline resistance.

Fluoroquinolones are highly effective as oral single dose treatment for gonorrhoea but reduced susceptibility and treatment failures with these agents have been recently reported. ${ }^{6}$ In Hong Kong, quinolone resistance in $N$ gon- orrhoeae (QRNG) increased from $0.5 \%$ in 1992 to $10.4 \%$ in 1994 and was associated with a rapid decline in prevalence of both PPNG and TRNG. $^{7}$

The present study was undertaken to determine the antibiotic susceptibility of $N$ gonorrhoeae isolates, to assess the prevalence of PPNG, and to study the plasmid profile of PPNG and non-PPNG strains.

\section{Material and methods}

BACTERIAL ISOLATES

Fifty consecutive isolates of $N$ gonorrhoeae recovered from 48 men with urethritis and two women with endocervicitis, attending the STD clinic of Lok Nayak Hospital, New Delhi, between May 1995 and March 1996 were studied.

For isolation of $N$ gonorrhoeae, urethral and endocervical specimens were directly inoculated in the STD clinic on modified ThayerMartin medium (GC agar base + haemoglobin + growth supplement + VCNT) and chocolate agar (GC agar + haemoglobin + growth supplement). The inoculated culture plates were incubated at $34-36^{\circ} \mathrm{C}$ in a humid atmosphere containing 3-10\% carbon dioxide (candle extinction jar) for 48-72 hours. Isolates were identified as $N$ gonorrhoeae on the basis of colony morphology, Gram staining, oxidase test, and carbohydrate degradation tests. ${ }^{8}$

Isolates were maintained by daily subculture on chocolate agar or by storage of a bacterial suspension in trypticase soya broth with $20 \%$ glycerol at $-20^{\circ} \mathrm{C}$. 
Table 1 MIC values of five antimicrobial agents for 46 non-PPNG isolates of $N$ gonorrhoeae

\begin{tabular}{|c|c|c|c|c|c|c|c|c|c|}
\hline Penicillin & $\mu \mathrm{g} / \mathrm{ml}$ & $\leqslant 0.15$ & 0.3 & 0.6 & 1.2 & 2.4 & 4.8 & $\geqslant 9.6$ & \\
\hline No of isolates & & 6 & 24 & 14 & - & 2 & - & - & \\
\hline Tetracycline & $\mu \mathrm{g} / \mathrm{ml}$ & $\leqslant 0.25$ & 0.5 & 1 & 2 & 4 & 8 & $\geqslant 16$ & \\
\hline No of isolates & & - & 12 & 6 & 0 & 8 & 10 & 10 & \\
\hline Norfloxacin & $\mu \mathrm{g} / \mathrm{ml}$ & $\leqslant 0.007$ & 0.015 & 0.03 & 0.06 & 0.12 & 0.25 & 0.5 & $\geqslant 1$ \\
\hline No of isolates & & - & 12 & 22 & - & 4 & 2 & - & 6 \\
\hline Ceftriaxone & $\mu \mathrm{g} / \mathrm{ml}$ & $\leqslant 0.007$ & 0.015 & 0.03 & 0.06 & 0.12 & 0.25 & 0.5 & $\geqslant 1$ \\
\hline No of isolates & & 42 & 2 & 2 & - & - & - & - & - \\
\hline Chloramphenicol & $\mu \mathrm{g} / \mathrm{ml}$ & $\leqslant 0.25$ & 0.5 & 1 & 2 & 4 & 8 & 16 & $\geqslant 32$ \\
\hline No of isolates & & - & - & - & 18 & 18 & 10 & - & - \\
\hline
\end{tabular}

Table 2 Correlation between plasmid profile and antimicrobial resistance in $N$ gonorrhoeae

\begin{tabular}{llcl}
\hline Plasmids (MDa) & $\begin{array}{l}\text { No (\%) of } \\
\text { strains }\end{array}$ & No of resistant strains & Type of antimicrobial resistance \\
\hline None & $10(20)$ & 4 & CMRNG Tet \\
2.6 & $24(48)$ & 14 & QRNG \\
$2.6+24.5$ & $2(4)$ & 2 & CMRNG Tet \\
$2.6+25.2$ & $10(20)$ & 6 & CMRNG Tet+CMRNG Pen \\
& & 4 & TRNG \\
$2.6+4.4+25.2$ & $4(8)$ & 4 & TRNG+QRNG \\
\hline
\end{tabular}

CMRNG Tet $=$ chromosomally mediated resistance in $N$ gonorrhoeae to tetracycline (MIC 2-8 $\mu \mathrm{g} / \mathrm{ml}) ;$ CMRNG Pen = chromosomally mediated resistance in $N$ gonorrhoeae to penicillin (MIC $\geqslant 1.2 \mu \mathrm{g} / \mathrm{ml}) ;$ TRNG $=$ tetracycline resistant $N$ gonorrhoeae $(\mathrm{MIC} \geqslant 16 \mu \mathrm{g} / \mathrm{ml}) ;$ PPNG = penicillinase producing $N$ gonorrhoeae; $\mathrm{QRNG}=$ quinolone resistant $N$ gonorrhoeae $(\mathrm{MIC} \geqslant 1 \mu \mathrm{g} / \mathrm{ml})$.

ANTIMICROBIAL SUSCEPTIBILITY TESTS

All $N$ gonorrhoeae isolates were tested for production of penicillinase by the paper acidometric method. ${ }^{9}$

Each isolate was examined for susceptibility to penicillin $(0.15-9.6 \mu \mathrm{g} / \mathrm{ml})$, tetracycline (0.25-16 $\mu \mathrm{g} / \mathrm{ml})$, chloramphenicol (0.25-32 $\mu \mathrm{g} / \mathrm{ml})$, norfloxacin and ceftriaxone (0.007-1 $\mu \mathrm{g} / \mathrm{ml})$ using the agar plate dilution method for determination of minimum inhibitory concentration (MIC). The bacterial suspension used as inoculum was prepared in Mueller-Hinton broth and consisted of approximately $10^{7} \mathrm{cfu} / \mathrm{ml}$. The medium employed for agar plate dilution tests was chocolate agar. ${ }^{8}$

The WHO $N$ gonorrhoeae reference strains A-E, kindly provided by Dr I Lind, Statens Seruminstitut, Copenhagen, were used as controls.

\section{PLASMID ANALYSIS}

All $N$ gonorrhoeae isolates were subjected to plasmid analysis by agarose gel electrophoresis with ethidium bromide staining. Plasmid DNA was extracted and purified from an overnight growth of $N$ gonorrhoeae on chocolate agar using a modification of the alkali lysis method. ${ }^{10}$ Electrophoresis was carried out in $0.7 \%$ agarose gel at $50 \mathrm{~V}$ for 3 hours allowing separation of plasmid DNA bands that were viewed by ultraviolet transilluminator. The distance moved by each plasmid band was measured directly from the gel and a photograph of the stained gel taken for permanent record. The relative mobility of each plasmid DNA band was calculated and its molecular weight derived.

Escherichia coli $\mathrm{V} 517$, containing plasmids of known molecular weight, was used as the molecular weight marker.

\section{Results}

The majority of male patients with gonorrhoea were between 15 and 30 years of age $(92 \%)$, were unmarried $(72 \%)$, and gave a history of having acquired the infection through contact with a commercial sex worker (94\%). Eighty four per cent had never used a condom, $98 \%$ were heterosexual, and $96 \%$ gave history of sexual promiscuity (more than two sexual partners). Concomitant syphilis was present in $20 \%$ of patients while chancroid and venereal warts were present in $4 \%$ of patients each.

\section{ANTIMICROBIAL SUSCEPTIBILITY}

Four (8\%) gonococcal isolates were found to be PPNG while $28 \%$ exhibited high level tetracycline resistance (TRNG) (MIC $\geqslant 16 \mu \mathrm{g} / \mathrm{ml}$ ). Reduced susceptibility to norfloxacin (MIC $\geqslant 1 \mu \mathrm{g} / \mathrm{ml}$ ) was detected in $12 \%$ of $N$ gonorrhoeae isolates, but was more frequent among strains that showed high level tetracycline resistance. All PPNG had a similar antimicrobial susceptibility profile with MIC values of penicillin $(\geqslant 9.6 \mu \mathrm{g} / \mathrm{ml})$ tetracycline $(\geqslant 16 \mu \mathrm{g} / \mathrm{ml})$, norfloxacin $(0.015 \mu \mathrm{g} / \mathrm{ml})$, ceftriaxone $(\leqslant 0.007 \mu \mathrm{g} / \mathrm{ml})$, and chloramphenicol (4 $\mu \mathrm{g} / \mathrm{ml})$.

Table 1 shows the MIC values of five antimicrobial agents for 46 non-PPNG isolates. The MIC 90 value of penicillin, tetracycline, and norfloxacin was found to be $0.6 \mu \mathrm{g} / \mathrm{ml}, \geqslant 16$ $\mu \mathrm{g} / \mathrm{ml}$, and $\geqslant 1 \mu \mathrm{g} / \mathrm{ml}$ respectively.

\section{PLASMID PROFILE}

The 2.6 MDa cryptic plasmid was present in $40(80 \%)$ gonococcal isolates, $10(25 \%)$ of them showed the concatameric $7.8 \mathrm{MDa}$ plasmid as well.

Table 2 shows the correlation between the plasmid profiles and antimicrobial resistance observed in the gonococcal isolates.

Four plasmid profiles could be distinguished among the 40 isolates that harboured plasmids. All TRNG isolates had the 25.2 MDa plasmid but two plasmid patterns could be seen among the 14 TRNG strains. Four $(28.5 \%)$ of the TRNG strains also exhibited reduced sensitivity to norfloxacin (MIC $\geqslant 1 \mu \mathrm{g} / \mathrm{ml} \mathrm{QRNG}$ ). All four PPNG isolates harboured the $4.4 \mathrm{MDa}$ Asian type of penicillinase encoding plasmid along with the $25.2 \mathrm{MDa}$ high level tetracycline resistance plasmid.

\section{Discussion}

In our study population we found $8 \%$ gonococcal isolates to be PPNG, although an earlier study in another hospital in Delhi found no PPNG among 102 isolates examined. ${ }^{11}$ The incidence of PPNG reported from other parts of India varies from $0-13.6 \%{ }^{12}$ but is reported to be as high as $59 \%$ from central Africa. ${ }^{5}$

All the PPNG strains in the present study harboured the $4.4 \mathrm{MDa}$ Asian type $\beta$ lactamase plasmid along with the $25.2 \mathrm{MDa}$ plasmid encoding for high level tetracycline resistance. This has not been reported in any previous Indian study, although one study observed the presence of the $4.4 \mathrm{MDa} \beta$ lactamase plasmid in all eight PPNG examined, accompanied by the 24.5 MDa large conjugative plasmid in three PPNG. ${ }^{2}$ In Spain the 4.5 MDa Asian type plasmid has been reported to be present in $92.8 \%$ of 
PPNG and the 24.5 MDa conjugative plasmid has also been found more frequently among PPNG than among non-PPNG $(85 \%$ v $25 \%){ }^{12}$

Plasmid mediated high level resistance to tetracycline, which was first observed in 1985 in the United States, ${ }^{3}$ has recently been reported in $10 \%$ of $N$ gonorrhoeae isolates in central Africa. ${ }^{5}$ The proportion of TRNG strains which were also PPNG varies from less than $1 \%{ }^{3}$ to $81 \% .^{5}$ We observed high level tetracycline resistance in $28 \%$ of gonococcal isolates and all of them harboured the 25.2 MDa plasmid. Four $(28.5 \%)$ of them were also PPNG, while four $(28.5 \%)$ were QRNG (MIC $\geqslant 1 \mu \mathrm{g} / \mathrm{ml}$ ). Two different plasmid profiles were observed among TRNG.

A decrease in susceptibility of gonococcal isolates to the fluoroquinolones has already been reported from Rwanda and Hong Kong. ${ }^{67}$ In our study, 12 (24\%) gonococcal isolates had an MIC of $\geqslant 0.06 \mu \mathrm{g} / \mathrm{ml}$, while six among these had an MIC of $\geqslant 1 \mu \mathrm{g} / \mathrm{ml}$ of norfloxacin. There is little information about the relation between the in vitro MIC of fluoroquinolones against gonococci and clinical efficacy except one study which found that failure with an $800 \mathrm{mg}$ single dose of norfloxacin occurred more often in patients with strains having MIC $\geqslant 0.06 \mu \mathrm{g} / \mathrm{ml} .{ }^{6}$ None of the studies mentioned the detection of quinolone resistance more frequently among TRNG or PPNG. However, we found norfloxacin resistance to be more frequent among TRNG strains compared with non-TRNG strains $(28.5 \%$ v $5.5 \%)$.

The results of our study indicate clearly that plasmid mediated resistance to penicillin and tetracycline is rapidly increasing as is resistance to quinolones which were introduced as first line therapy only around 1990. Currently, ceftriaxone is being preferred as first line therapy but unless continued monitoring of antimicrobial susceptibility of gonococcal strains circulating in a community is carried out, treatment failures may occur and lead to prolonged infectiousness and spread of multiresistant strains of $N$ gonorrhoeae.

1 Mishra D, Singh G. Penicillinase producing Neisseria gonorrhoeae infection in India. Ind $\mathcal{f}$ Sex Transm Dis 1989;10:45-7.

2 Kulkarni MG, Roche RA, Murti PK, et al. Auxotyping, susceptibility pattern and plasmid profile of gonococcal isolates. Ind $\mathcal{F}$ Sex Transm Dis 1989;10:53-6.

3 Centers for Disease Control. Tetracycline-resistant Neisseria gonorrhoeae-Georgia, Pennsylvania, New Hampshire. MMWR 1985;34:563-70.

4 Ison C, Terry P, Bindayna K, Gill M, et al. Tetracycline resistant gonococci in UK. Lancet 1988;1:651-2.

5 Van Dyck E, Rossau R, Duhamel M, et al. Antimicrobia susceptibility of Neisseria gonorrhoeae in Zaire: high level plasmid-mediated tetracycline resistance in central Africa Genitourin Med 1992;68:111-16.

6 Bogaerts J, Tello WM, Akingeneye J, et al. Effectiveness of norfloxacin and ofloxacin for treatment of gonorrhoea and decrease of in vitro susceptibility to quinolones over time in Rwanda. Genitorurin Med 1993;69:196-200.

$7 \mathrm{Kam} \mathrm{KM}$, Lo KK, Ho Ng KY, et al. Rapid decline in penicillinase producing N gonorrhoeae in Hong Kong associated with emerging 4-fluoroquinolone resistance. Genitoated with emerging 4-flu
urin Med 1995;71:141-4.

8 Van Dyck E, Piot P, Meheus A. Bench level laboratry manual for sexually transmitted diseases. WHO/VDT, 1989:443.

9 Sng EH, Yeo KL, Rajan VS. Simple method for detecting penicillinase producing Neisseria gonorrhoeae and Staphylococcus aureus. Br 7 Vener Dis 1981;57:141-2.

10 Birnboim HC, Doly J. A rapid alkaline extraction procedure for screening recombinant plasmid DNA. Nucleic Acids Res 1979;7:1513-23.

11 Agarwal SK, Deb M, Prakash K, et al. Auxotyping of Neisseria gonorrhoeae as an additional epidemiological marker. Ind $\mathcal{F}$ Med Res 1992;95:227-9.

12 Palomares JC, Lozano MC, Perca EJ. Antibiotic resistance, plasmid profile, auxotypes and serovars of Neisseria gonorrhoeae strains isolated in Sevilla (Spain). Genitourin Med 1990;66:87-90. 